\title{
Teachers' Intention towards the Usage of Technology: An Investigation Using UTAUT Model
}

\author{
Shazma Nandwani *
}

\author{
Sadiq Ali Khan ${ }^{\dagger}$
}

\begin{abstract}
The purpose of this study is to explore the vital factors that influence teacher's intention to use technology in higher education. PLS-SEM has been used to analyze the data collected from 201 business university teachers. The study strives to examine the impact of eight variables i.e. Performance expectancy, Effort Expectancy, Social influence, facilitating conditions, individual self-efficacy, human assisted self-efficacy, Computer Anxiety and attitude on teacher's intention to use technology using the technology acceptance model of Unified Theory of Acceptance and Usage of Technology. The empirical findings revealed that the social influence, facilitating conditions, individual self-efficacy and attitude have the significant and positive impact, while computer anxiety has a negative significant impact on the intention to use technology. However, performance expectancy, effort expectancy and human assisted self-efficacy have an insignificant impact on teacher's intention to use technology. The present study provides an inclusive view to understanding the acceptance of technology by teachers. The strength of present research lies in studying the extended version of UTAUT which will guide the university administrators and policy makers in understating those factors that influence the technology acceptance among teachers.
\end{abstract}

Keywords: UTAUT; teachers' intention; Higher education; technology usage; Pakistan.

\section{Introduction}

The young generation is one of the main users of the technology and considered as driven achievers; highly depended on technology, especially for study and learning (Williams, Warner, Flowers, \& Croom, 2014). The prominence of a blackboard, chalks, and textbooks are still significant for education, but younger students also need technology enhanced classroom because they are born in this digital age (Williams et al., 2014). Therefore, in order to engage the student, the technology should be adopted in the education system i.e. schools, colleges and universities (Munro, 2012).

The technology acceptance is very important to be successful in this fast pace and century of technology. Many technologies that are considered as useful and usable, but do not succeed because of the non-acceptance by the users (Dillon, 2001). In the educational sector, the technology adoption is weak because the teachers are not willing to use technology (Hadjipavli, 2011; Stantchev, ColomoPalacios, Soto-Acosta, \& Misra, 2014).

Many studies have been conducted by the educational researchers to investigate the factors which affect the teacher's adoption towards the technology (Kim, Jung, \& Lee, 2008; Mueller, Wood, Willoughby, Ross, \& Specht, 2008). Several factors affect the technology adoption in the education system by the teachers. The individual factors include attitudes towards the use of technology (Cviko, McKenney, \& Voogt, 2012), technology anxiety (Wood, Mueller, Willoughby, Specht, \& Deyoung, 2005) and environmental factors i.e., facilitating conditions (Ngai, Poon, \& Chan, 2007). Venkatesh, Morris, Davis, and Davis (2003) the most critical factors which affect the behavioral intention of the individual to use the technology as performance expectations, effort

\footnotetext{
*Faculty of Education and Learning Sciences, Iqra University, Karachi, Pakistan.

Email: shazmanandwani@hotmail.com

${ }^{\dagger}$ Department of Computer Sciences, University of Karachi, Karachi, Pakistan.
} 
expectancy, social influence and facilitating conditions. Along with this the other variables, which include self-efficacy, attitude, and computer anxiety also affects the individual intention to use the technology.

Performance expectancy is the person's believe that using the technology will help them to improve their job performance (Venkatesh et al., 2003). Effort expectancy. It is the person's believe that using the technology is effortless (Raman \& Don, 2013). Social influence is the perceived social pressure on the individual to do or not to do the certain actions. It is the individuals' perception that how the people close to them will approve or disapprove the required action of the individual (Ajzen, 1991). Self-efficacy is the personal judgment of the individual regarding its skills to perform a particular task (Bandura, 1986). Moreover, a computer related self-efficacy (CSE) helps in adopting a new technology (D. R. Compeau \& Higgins, 1995). Facilitating conditions are the technical support available to use the new technology (Venkatesh et al., 2003). Attitude is the individual reactions regarding the technology usage (Ajzen, 1991). Computer anxiety is the anxiety aroused because of the interaction with the computer.

In the past, many studies have been conducted to examine the role of behavioral intention on technology adoption by using the TAM model (Hu, Chau, Sheng, \& Tam, 1999) and UTAUT models (Sundaravej, 2010; Thomas, Singh, \& Gaffar, 2013; Baleghi-Zadeh, Ayub, Mahmud, \& Daud, 2014). Many studies reported that performance expectancy, effort expectancy, social influence and facilitating conditions exert an influence to adopt the technology (Venkatesh, Thong, \& Xu, 2012). However, some studies also reported that factors like attitude (Cviko et al., 2012), computer anxiety (Hasan \& Ahmed, 2012) and self-efficacy (Teo, 2009) which includes individual self-efficacy and human assisted self-efficacy affects the individual intention to adopt the technology.

In Pakistan the importance of technology for teachers are emphasized in National Professional Standards for Teachers in Pakistan (2009), According to its standard number 7 i.e., Effective Communication and Proficient Use of Information and Communication Technology, a teacher should be proficient and capable of using the technology but still very few practical initiatives have been observed in its implementation and dedicated use of technology in the education sector. According to the report by National Education Management Information System (NEMIS), Academy of Educational Planning and Management of Pakistan(AEPM), the country educational sector is weak. The higher education sector comprises of 163 universities in which 91 (56\%) are public sector universities whereas $72(44 \%)$ are private sector. The teachers working in the universities are 88,288 in which 70,078 (79\%) are working in the public sector and 18,210 (21\%) are working in private sectors (NEMIS, 2014-2015). According to National Business Education Accreditation Council (NBEAC), 2015 in total, there are total 99 business universities in Pakistan, out of which 28 are located in Sindh and in these 28 business universities 22 are situated in Karachi.

In the last decade the prime concern of the Higher Education commission of Pakistan (HEC) is, to do professional development of teachers in higher education institutions. Various measures were initiated by the HEC which included teacher training, research grants, provision of technology and much more which brings in a positive change in the teachers, but still, few challenges and issues need to be explored (Aslam, 2011). One of the core issues found in the education system of Pakistan is the acceptance of the technology. According to the Global Information Technology Report (2015), Pakistan is at a position of 97th during the year 2014-2015 in adopting technology. In order to increase the technology acceptance among the younger generation, the teachers should be focused. They should be facilitated to enhance their technological skills and work on their professional development. Because improving teacher's capability and skills have a sustainable effect on the youngster's overall education.

Many studies have been conducted on the usage of technology adoption in the educational institutions based on the UTAUT model (Imtiaz \& Maarop, 2014; Abbasi, Tarhini, Elyas, \& Shah, 2015) and most of the studies on teachers' intention to use the technology has been done at the 
school level (Teo \& Noyes, 2011; Teo \& Milutinovic, 2015) and in developed economies. However, no study has been conducted in Pakistan scenario in the context of technology acceptance in the education sector which uses the modified UTAUT model. Therefore, a research gap exists in the literature, so this study will fulfill the gap. The study will re-investigate the factors which affect the teacher intention to adopt the technology in the higher education, business administration institutions of Karachi, Pakistan by using modified UTAUT model.

This study examines the role of all the four variables of the UTAUT model (Performance expectancy, Effort expectancy, Social influence, facilitating conditions) as well as the addition of four more variables (individual self-efficacy, human assisted self-efficacy, computer anxiety and attitude) which makes it the modified UTAUT model to examine the relationship. Besides; the role of selfefficacy (individual self-efficacy \& human assisted self-efficacy), computer anxiety, and attitude on the teachers' adoption of technology. As the teachers of higher education institutes need to have the competencies to work with advanced and complex qualitative and quantitative statistical software's, so they must feel self-sufficient and if they are provided with some human assistance which will facilitate them to learn that technology related software's this may reduce their anxiety and facilitate them in forming their attitudes to using the technology at their work. The technology acceptance theories like Theory of Reasoned Action (TRA) 1975 and Theory of Planned Behavior (TPB) 1985, explains that attitude develops the intention. This study will help to answer the question whether the non-adoption of technology by teachers is due to those factors or not. The rationale behind choosing this population was the identification of teacher's intention in higher education institutions towards the use of technology hence, there are many public and private business institutions in Karachi therefore, the better results and conclusions can be obtained and drawn from the study.

The paper has been organized into five sections viz. Introduction; review of existing literature; methodology; estimations and results, while the last section provides conclusion and recommendations of the study.

\section{Literature Review}

There are various technology acceptance models which have been used in the past by different researchers but the two prominent models used in the past were Technology Acceptance Model (TAM) and Unified Theory of Acceptance and Use of Technology (UTAUT).

\section{Theoretical Background}

The theory of TAM was given by Davis (1989) to hypothesize the individual behavior towards the technology usage. TAM was basically based on the theory, namely the theory of reasoned action given by Ajzen (1991). TAM explains the factors which affect the acceptance of computer technology among the users (Davis, Bagozzi, \& Warshaw, 1989). TAM uses the attitude construct of TRA by further dividing it into two factors that are perceived usefulness and perceived ease of use. These factors were used to explore the technology acceptance behavior of the users. According to TAM, these both factors create an impact on the individual attitude which ultimately affects the individual intentions.

This study has been based on the cores of the Unified Theory of Acceptance and Use of Technology (UTAUT). UTAUT is the most inclusive and comprehensive technology acceptance theory (Afshan \& Sharif, 2016) as it integrates the constructs of eight prominent technology acceptance models streamlining their limitations. Since there is no single model that covers all or even maximum constructs affecting the acceptance of technology; Venkatesh et al. (2003) studied eight technology acceptance models which include the Theory of Reasoned Action (TRA), the Technol- 
ogy Acceptance Model (TAM), the Motivational Model (MM), the Theory of Planned Behavior (TPB), a model combining the Technology Acceptance Model and the Theory of Planned Behavior (C-TAM-TPB), the Model of PC Utilization (MPCU), the Innovation Diffusion Theory (IDT) and the Social Cognitive Theory (SCT) and gave a unified model of technology acceptance which they called Unified Theory of Acceptance and Use of Technology (UTAUT). UTAUT accounted for 70\% of the variance which is higher than the eight original models studied which explained the variance between $17 \%$ to $53 \%$ only (Venkatesh et al., 2003). Likewise, Kim et al. (2008) also explained in their study that UTAUT in comparison to TAM and TPB showed highest variance among any of the intention model.

Venkatesh et al. (2003) reviewed all the eight acceptance models and came across 32 constructs in original theories that have effects on intention and usage of individuals toward technology. After studying the 32 constructs, they identified seven constructs which had the similar meaning and definition in the context of the theory. They termed the seven constructs as Performance Expectancy, Effort Expectancy, Social Influence, Facilitating Conditions Self-Efficacy, Computer Anxiety and Attitude Toward Using Technology.

Venkatesh et al. (2003) hypothesized that there are three core constructs which have the direct impact on behavior intentions, which are Performance Expectancy, Effort Expectancy and Social Influence while one core construct of Facilitating Conditions has a direct impact on Usage Behavior of technology. Further, there are three indirect determinants of intention which includes SelfEfficacy, Computer Anxiety and Attitude towards using technology. Moreover, this study also focuses on moderating variables, which include Experience, Voluntariness, Gender and Age that have an impact on four core constructs of UTAUT. In UTAUT, Self-Efficacy and Anxiety are included as an indirect determinant of intention (Venkatesh et al., 2003).

In the domain of educational technology, various researchers have conducted their studies based on the UTAUT model such as (Abbasi et al., 2015; Imtiaz \& Maarop, 2014; Teo \& Zhou, 2014).

\section{Empirical Studies}

\section{Performance expectancy}

Studies suggest that performance expectancy has positive (Wong, Teo, \& Russo, 2013) significant (Teo \& Milutinovic, 2015; Wong, Goh, \& Rahmat, 2013) direct effect (Ma, Andersson, \& Streith, 2005; Ngai et al., 2007) with the intention to use technology and its acceptance. However, Atkinson and Kydd (1997) reported that performance expectancy does not have a significant impact on the intention to use technology. Past studies imply that if the user will be more willing to use and adopt the technology if he assumes it to be useful for improving his performance.

H1: Performance Expectancy has a significant impact on the behavioral intention of the teachers.

\section{Effort expectancy}

The relationship of effort expectancy with intention to use technology has been viewed in literature as positive (Teo \& Zhou, 2014) significant (Teo \& Milutinovic, 2015; S.-C. Chen, Liu, Li, \& Yen, 2013) and having a direct effect (Teo \& Zhou, 2014; Teo, Lee, \& Chai, 2008) on intention which means the users perceive that the usage of technology reduces the efforts they put into their work which increases their intention to use technology resultantly. Moreover, some studies reported that effort expectancy has an indirect relation with intention to use technology (Teo, 2009; Anderson \& Gerbing, 1988).

H2: Effort Expectancy has a significant impact on the behavioral intention of the teachers. 


\section{Social influence}

Social influence is when people like relatives, friends and celebrities influence an individual to use technology (Arif, Aslam, \& Ali, 2016). Varied effects of social influence on intentions to use technology have been reported in literature. Ma et al. (2005) and Wong, Teo, and Russo (2013) have reported an insignificant effect of social influence on intention and Teo et al. (2008) while Teo and Zhou (2014) have reported indirect effect. However, significant effects of social influence on intentions have also been reported (He \& Freeman, 2010; Teo \& Milutinovic, 2015). Social influence implies that the peers; colleagues or friends that have an influence on individuals either advocates or discourage the technology usage.

H3: Social Influence has a significant impact on the behavioral intention of the teachers.

\section{Facilitating conditions}

Facilitating conditions have been reported as having indirect (Teo \& Zhou, 2014; Teo, 2009) and insignificant (Wong, Goh, \& Rahmat, 2013; Teo et al., 2008; Ngai et al., 2007) effect on intention to use technology, but some studies have reported the significant effect on intention (Teo \& Milutinovic, 2015). The support of the environment and surroundings assists the individual in accomplishing the tasks using technology.

H4: Facilitating Conditions has a significant impact on the behavioral intention of the teachers.

\section{Attitude}

Significant direct effect of attitude on intention have been reported in the previous studies (Teo, 2009; Teo \& Zhou, 2014; Teo, 2009). Moreover, research has also reported the indirect effect on intention to use technology (Chau, 2001; Teo \& Milutinovic, 2015). Attitude amplifies the effect of other factors on the intention to use technology. (H.-R. Chen \& Tseng, 2012) have reported the negative effect of computer anxiety on intention to use technology. (Alenezi, Karim, \& Veloo, 2010) reported a significant effect and Teo (2009) identified the indirect effect.

H5: Attitude has a significant impact on the behavioral intention of the teachers.

\section{Computer anxiety}

Insignificant effects of computer anxiety on intention have been stated (Igbaria \& Iivari, 1995). Alenezi et al. (2010) have reported significant impact of computer anxiety on student's intention to adopt technology. Furthermore, (H.-R. Chen \& Tseng, 2012) have reported the negative effect of computer anxiety on intention to use technology.

H6: Computer anxiety has a significant impact on the behavioral intention of the teachers.

\section{Self-efficacy}

Self-efficacy has significant direct and positive effects on intention to use technology (He \& Freeman, 2010; Alenezi et al., 2010; Igbaria \& Iivari, 1995; Henry \& Stone, 1994; H.-R. Chen \& Tseng, 2012). The indirect effect of self-efficacy on intention has also been reported in studies (John, 2013; Teo \& Zhou, 2014). Self-efficacy is one of the factors which has strong effects on intention by enhancing the person's self-image.

H7: Individual Self-efficacy has a significant impact on the behavioral intention to of the teachers.

H8: Human Assisted Self-efficacy has a significant impact on the behavioral intention of the teachers. 


\section{Methodology}

The conceptual model of the study is given below.

Figure 1

Research model

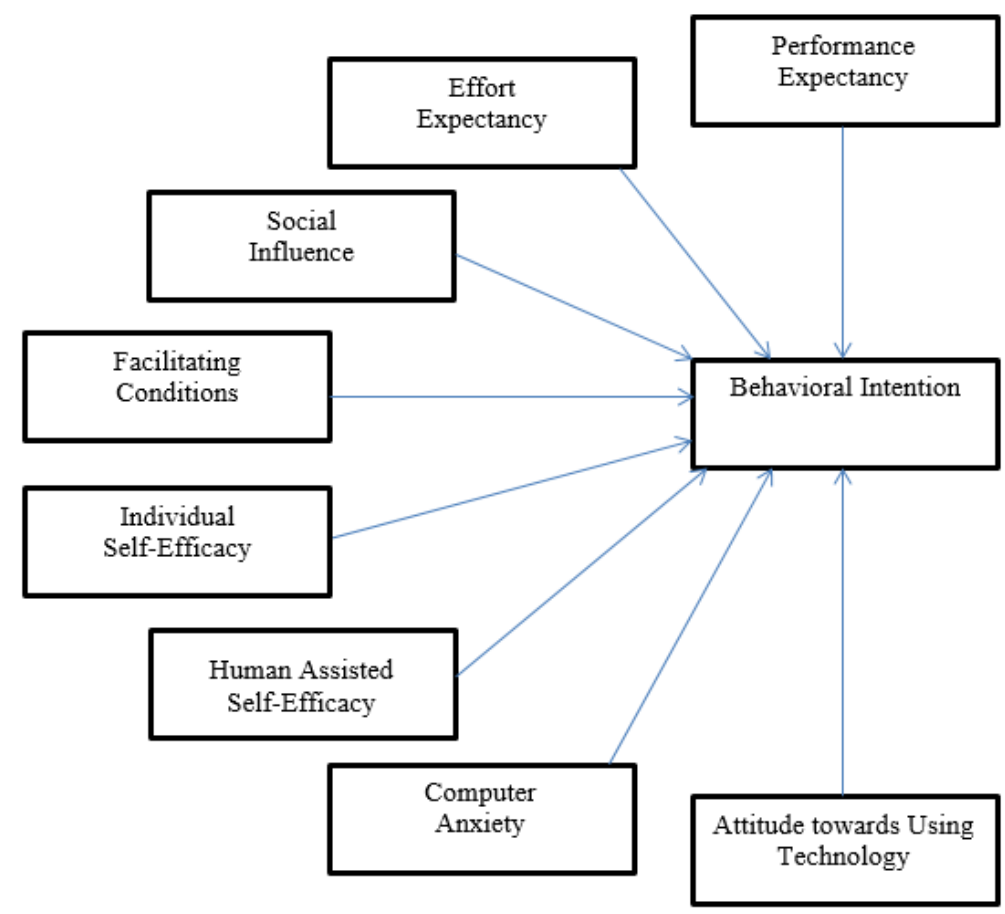

In this study the UTAUT model has been modified by adding four more variables. The questionnaire of the study consists of 35 items which were contextualized and modified. The instrument was also tested by pilot study to confirm the reliability. The data were collected from the teachers of 18 business schools of the Karachi on the basis of their willingness and availability via survey method. For the entry of collected data, a data template was developed using Statistical Package for Social Sciences (SPSS) version 22. The questionnaire contained nine variables in which eight were dependent variables and one was the independent variable in which the responses of participants were coded as per the five-point Likert scale in which $1=$ Strongly Disagree. $2=$ Disagree, 3 $=$ Neutral, $4=$ Agree, and $5=$ Strongly Agree. The demographic data was also collected through the questionnaire which included type / sector of university, years of teaching experience, higher qualification completed at the moment of responding to the questionnaire by the participant, gender of the participant, competencies in IT (Information Technology) software's, competencies in qualitative and quantitative research software's, last qualification completed from national or international university, academic designation of the participant, any administrative responsibilities held by the participant and published research contribution of the participant. 


\section{Estimations and Results}

The profile of research participants is given in table 1 . The table provides the complete academic information of the research participants, $71 \%$ of the respondents were from private sector universities while $29 \%$ teachers from the public sector. There were $65 \%$ male and $35 \%$ female participated in the study.

Table 1

Profile of respondents $(\mathrm{N}=201)$

\begin{tabular}{|c|c|c|}
\hline Demographic items & Frequency & Percentile \\
\hline \multicolumn{3}{|l|}{ Sector of University } \\
\hline Public Sector & 58 & $29 \%$ \\
\hline Private Sector & 143 & $71 \%$ \\
\hline \multicolumn{3}{|l|}{ Years of teaching experience } \\
\hline Less than one year & 56 & $28 \%$ \\
\hline One to three years & 64 & $32 \%$ \\
\hline Four to six years & 35 & $17 \%$ \\
\hline Seven to ten years & 25 & $13 \%$ \\
\hline Eleven and above years & 21 & $10 \%$ \\
\hline \multicolumn{3}{|l|}{ Highest qualification completed } \\
\hline Post Doctorate & 2 & $1 \%$ \\
\hline Doctor of Philosophy (Ph.D.) & 19 & $10 \%$ \\
\hline Master of Philosophy (MS/M.Phil - Eighteen years of Education & 131 & $65 \%$ \\
\hline Masters (Sixteen years of education) & 49 & $24 \%$ \\
\hline \multicolumn{3}{|l|}{ Gender } \\
\hline Male & 130 & $65 \%$ \\
\hline Female & 74 & $35 \%$ \\
\hline \multicolumn{3}{|l|}{ Competencies in Information Technology (IT) software } \\
\hline Microsoft Office Package (Excel, Power point and Word) & 186 & $93 \%$ \\
\hline Microsoft Project & 13 & $6 \%$ \\
\hline Computer Programming Languages & 2 & $1 \%$ \\
\hline \multicolumn{3}{|l|}{ Competencies in quantitative and qualitative research software } \\
\hline SPSS (Statistical Package for Social Sciences) & 110 & $55 \%$ \\
\hline E-Views (Econometric Views) & 37 & $18 \%$ \\
\hline MATLAB (Matrix Laboratory) & 24 & $12 \%$ \\
\hline AMOS (Analysis of Moment Structures) & 19 & $9 \%$ \\
\hline R (Statistical Programming Language) & 6 & $3 \%$ \\
\hline LISREL (Linear Structural Relations) & 3 & $2 \%$ \\
\hline Qualitative Software (ex. NViVo) & 2 & $1 \%$ \\
\hline \multicolumn{3}{|l|}{ Last qualification completed from } \\
\hline Pakistan & 181 & $90 \%$ \\
\hline Abroad & 20 & $10 \%$ \\
\hline \multicolumn{3}{|l|}{ Academic designation } \\
\hline Full Professor & 6 & $3 \%$ \\
\hline Associate Professor & 17 & $8 \%$ \\
\hline Assistant Professor & 40 & $20 \%$ \\
\hline Senior Lecturer & 41 & $21 \%$ \\
\hline Lecturer & 97 & $48 \%$ \\
\hline \multicolumn{3}{|l|}{ Administrative responsibility } \\
\hline Have Administrative Responsibilities & 56 & $28 \%$ \\
\hline Did not Have Administrative Responsibilities & 145 & $72 \%$ \\
\hline \multicolumn{3}{|l|}{ Published research contribution } \\
\hline No published research paper & 115 & $57 \%$ \\
\hline One to four published research paper(s) & 59 & $29 \%$ \\
\hline Five to ten published research papers & 18 & $9 \%$ \\
\hline More than ten published research papers & 9 & $5 \%$ \\
\hline
\end{tabular}




\section{Data Analysis PLS - SEM}

The partial least squares structural equation modeling (PLS-SEM) was used to analyze the research model (Figure 1). It was developed by Joreskog and Wold (1979). PLS-SEM is preferred over other covariance-based techniques such as multiple regressions, structural equation modeling (SEM) (Hair, Ringle, \& Sarstedt, 2011) because PLS-SEM uses a component-based method which is like principal components factor analysis (D. Compeau, Higgins, \& Huff, 1999). It is appropriate for the data with non-normal distributions (Falk \& Miller, 1992). Like covariance-based SEM, the PLS-SEM has the ability to work with latent variables that are observable and can describe the measurement error. Moreover, the relationship among multiple latent variables can be developed using PLS-SEM (Chin, 1998).

In our study, most of the variables are perception-based and their distribution is not known and as such their normality cannot be confirmed, so it is preferable over SEM. According to (D. R. Compeau \& Higgins, 1995) PLS-SEM is best suited when the dataset lies under the situation of multicollinearity, small sample size and non-normality. Thus, PLS-SEM is suitable when the normality assumption is in doubt and the sample size is also small (Fornell \& Bookstein, 1982). Lohmöller (1989) showed an example in which the model has 26 constructs and 96 items and was estimated on 100 sample size through this method. Therefore, this is best suited in our case also as we have 9 constructs, 42 items and the sample size of 201. To get reliable results from PLS-SEM a sample-size between 100 and 150; is considered reliable (Kline, 2005). SmartPLS 3 was used to assess the model (Ringle, Wende, \& Becker, 2015).

\section{Individual item reliability analysis}

Individual item reliability is the relationships of the items with their relevant variable construct. To check the individual reliability, generally, the loading at 0.7 or above is considered as an accepted rule by many researchers and also observed in studies. According to Nunally (1967), the items that have low loadings should be scrutinized and excluded as it has little power to explain the model. (Hulland \& of Business, 1999) reported that that the items which have loadings less than 0.4 or 0.5 should be eliminated. Fornell and Larcker (1981) said that the loading cut-off point should be 0.70 whereas(Chin, 1998) gave loading cut-off point of 0.707 . Some studies also use 0.5 loading as their cut-off point (Chin, 1998).

In our study as seen from table 2 , all the items have loading above 0.7 which is in accordance with the criteria given by (Fornell \& Larcker, 1981) except for CA1 and PE4. These two items reliabilities are in accordance with the cut-off point given by (Tabachnick \& Fidell, 2001) i.e., 0.55. These results concluded that all the items displayed the satisfactory level of reliability and are statistically significant.

\section{Convergent validity}

According to (Hulland \& of Business, 1999) when the multiple items are used then the researcher should not only focus on the individual item reliability but also examined the convergent validity. Convergent validity assesses the internal consistency. In PLS-SEM the convergent validity is measured by two ways:

(1) Composite Reliability Scores and Cronbach's alpha

(2) Average Variance Extracted (A.V.E.)

The consistency of coefficient is explained by Cronbach's alpha. It evaluates how precisely the set of items evaluated a particular one-dimensional latent construct. It means that when the data have multidimensional structure; the Cronbach's alpha is low in value. Composite reliability is similar to Cronbach's alpha but Composite reliability is better than Cronbach's Alpha because it uses the loading of the items found within the theoretical model (Fornell \& Larcker, 1981). The 
Cronbach's Alpha treated all the items equal without seeing their factor loadings. However, the interpretation is same for both composite reliability and Cronbach's Alpha. Churchill Jr (1979) gave the Cronbach's Alpha value cutoff pint 0.6 and (Nunally, 1967) gave the composite reliability cut-off point at 0.7 .

As seen in Table 2 below, the Cronbach's Alpha is greater than 0.6 which meets the benchmark given by (Churchill Jr, 1979) which means that all the variables showed satisfactory reliability (Ali \& Raza, 2015; Raza \& Hanif, 2013). The composite reliability is also greater than 0.7 which is in accordance with the criteria given by (Nunally, 1967). Thus, this means that individual items are appropriate for their respective latent variables.

Subsequently, the Average Variance Extracted (AVE) is assessed. AVE evaluated the degree of variance the latent variable acquires from its items compared to the degree of variance due to measurement errors. According to the (Fornell \& Larcker, 1981), the AVE should be higher than 0.5 which implies that latent variable should capture at least $50 \%$ of the measurement variance. As seen from the table 2 all the variables meet the (Fornell \& Larcker, 1981) criteria and have a value greater than 0.5 .

Table 2

Measurement Model Results

\begin{tabular}{|c|c|c|c|c|c|}
\hline Constructs & Items & Loadings & $\begin{array}{c}\text { Cronbach's } \\
\alpha\end{array}$ & $\begin{array}{l}\text { Composite } \\
\text { reliability }\end{array}$ & $\begin{array}{c}\text { Average } \\
\text { variance } \\
\text { extracted } \\
(\mathrm{AVE})\end{array}$ \\
\hline \multirow{4}{*}{ Performance Expectancy } & PE1 & 0.889 & 0.815 & 0.865 & 0.622 \\
\hline & PE2 & 0.910 & & & \\
\hline & PE3 & 0.720 & & & \\
\hline & $\mathrm{PE} 4$ & 0.592 & & & \\
\hline \multirow{4}{*}{ Effort Expectancy } & EE1 & 0.874 & 0.876 & 0.914 & 0.726 \\
\hline & EE2 & 0.881 & & & \\
\hline & EE3 & 0.808 & & & \\
\hline & EE4 & 0.842 & & & \\
\hline \multirow{4}{*}{ Social Influence } & SI1 & 0.901 & 0.873 & 0.912 & 0.722 \\
\hline & SI2 & 0.784 & & & \\
\hline & SI3 & 0.889 & & & \\
\hline & SI4 & 0.820 & & & \\
\hline \multirow{3}{*}{ Facilitating Conditions } & $\mathrm{FC} 2$ & 0.876 & 0.892 & 0.933 & 0.822 \\
\hline & FC3 & 0.916 & & & \\
\hline & $\mathrm{FC} 4$ & 0.927 & & & \\
\hline \multirow{4}{*}{ Individual assisted Self-efficacy } & ISE1 & 0.784 & 0.909 & 0.936 & 0.785 \\
\hline & ISE2 & 0.947 & & & \\
\hline & ISE3 & 0.938 & & & \\
\hline & ISE4 & 0.865 & & & \\
\hline \multirow{4}{*}{ Human assisted Self-efficacy } & HSE1 & 0.873 & 0.831 & 0.887 & 0.662 \\
\hline & HSE2 & 0.788 & & & \\
\hline & HSE3 & 0.783 & & & \\
\hline & HSE4 & 0.807 & & & \\
\hline \multirow{4}{*}{ Computer anxiety } & CA1 & 0.69 & 0.858 & 0.904 & 0.705 \\
\hline & $\mathrm{CA} 2$ & 0.859 & & & \\
\hline & $\mathrm{CA} 3$ & 0.882 & & & \\
\hline & CA4 & 0.910 & & & \\
\hline \multirow{4}{*}{ Attitude } & AT1 & 0.901 & 0.912 & 0.938 & 0.792 \\
\hline & AT2 & 0.910 & & & \\
\hline & AT3 & 0.820 & & & \\
\hline & AT4 & 0.924 & & & \\
\hline \multirow{4}{*}{ Intention } & I1 & 0.92 & 0.954 & 0.967 & 0.88 \\
\hline & $\mathrm{I} 2$ & 0.949 & & & \\
\hline & I3 & 0.940 & & & \\
\hline & I4 & 0.942 & & & \\
\hline
\end{tabular}

Source: Author estimations 
Hence, it is concluded from the above results that the measurement model showed the internal consistency and has convergent validity.

\section{Discriminant Validity}

Once the individual item reliability analysis and convergent validity is complete the next step is to evaluate the discriminant validity with the measurement model. The purpose of the discriminant validity is to determine the extent to which one variable differs from the other taken of the model. The discriminant validity is ensured by two tests (Chin, 1998).

(1) Analysis of cross loadings; and

(2) Analysis of average variance extracted (A.V.E.).

The rule used to analyze cross loading is that the items must highly associate with the variable that it will measure than the rest of the variables in the study. As seen from table 3 all the items have loading higher in their relevant variable construct. The cross-loading analysis showed that all the 35 items loaded particularly in their specified variable they calculated, Thus, proving the discriminant validity of the 9 variables.

Table 3

Loadings and Cross Loadings

\begin{tabular}{|c|c|c|c|c|c|c|c|c|c|}
\hline & AT & CA & EE & FC & HSE & I & ISE & PE & SI \\
\hline AT1 & 0.900 & & & & & & & & \\
\hline AT2 & 0.910 & & & & & & & & \\
\hline AT3 & 0.819 & & & & & & & & \\
\hline AT4 & 0.924 & & & & & & & & \\
\hline CA1 & & 0.689 & & & & & & & \\
\hline $\mathrm{CA} 2$ & & 0.858 & & & & & & & \\
\hline CA3 & & 0.882 & & & & & & & \\
\hline CA4 & & 0.910 & & & & & & & \\
\hline EE1 & & & 0.873 & & & & & & \\
\hline EE2 & & & 0.881 & & & & & & \\
\hline EE3 & & & 0.808 & & & & & & \\
\hline EE4 & & & 0.842 & & & & & & \\
\hline $\mathrm{FC} 2$ & & & & 0.875 & & & & & \\
\hline FC3 & & & & 0.916 & & & & & \\
\hline $\mathrm{FC} 4$ & & & & 0.926 & & & & & \\
\hline HSE1 & & & & & 0.872 & & & & \\
\hline HSE2 & & & & & 0.788 & & & & \\
\hline HSE3 & & & & & 0.783 & & & & \\
\hline HSE4 & & & & & 0.806 & & & & \\
\hline I1 & & & & & & 0.920 & & & \\
\hline I2 & & & & & & 0.948 & & & \\
\hline I3 & & & & & & 0.939 & & & \\
\hline I4 & & & & & & 0.942 & & & \\
\hline ISE1 & & & & & & & 0.784 & & \\
\hline ISE2 & & & & & & & 0.946 & & \\
\hline ISE3 & & & & & & & 0.938 & & \\
\hline ISE4 & & & & & & & 0.865 & & \\
\hline PE1 & & & & & & & & 0.889 & \\
\hline PE2 & & & & & & & & 0.910 & \\
\hline PE3 & & & & & & & & 0.719 & \\
\hline PE4 & & & & & & & & 0.592 & \\
\hline SI1 & & & & & & & & & 0.901 \\
\hline SI2 & & & & & & & & & 0.784 \\
\hline SI3 & & & & & & & & & 0.889 \\
\hline SI4 & & & & & & & & & 0.819 \\
\hline
\end{tabular}

Another measure through which the discriminant validity is assessed is looking at the Average Variance Extracted (AVE). The rule of thumb for AVE is that the variable should have more variance in its relevant construct than other variables in the model. According to the (Fornell \& 
Larcker, 1981), the AVE of the variable should be higher than the variance shared between the latent variable and other latent variables. This implies that the square root of the AVE should be greater than the values in the relevant constructs (i.e., correlation of two latent variables). The diagonal part of the table should be greater than the off-diagonal part. As seen from table 4 the results meet the criteria, no association is found between the variables higher or equal to the square root AVEs of the two variables. Thus, showed that all the variables are different from each other and model satisfies the discriminant validity criteria.

Table 4

Correlation Matrix

\begin{tabular}{llllllllll}
\hline & AT & CA & EE & FC & HSE & I & ISE & PE & SI \\
\hline AT & 0.890 & & & & & & & & \\
CA & 0.408 & 0.84 & & & & & & & \\
EE & 0.325 & 0.319 & 0.852 & & & & & & \\
FC & 0.411 & 0.525 & 0.232 & 0.907 & & & & & \\
HSE & 0.446 & 0.395 & 0.301 & 0.352 & 0.814 & & & & \\
I & 0.514 & 0.549 & 0.307 & 0.524 & 0.402 & 0.938 & & & \\
ISE & 0.450 & 0.333 & 0.237 & 0.463 & 0.406 & 0.540 & 0.886 & & \\
PE & 0.381 & 0.483 & 0.252 & 0.404 & 0.198 & 0.383 & 0.281 & 0.789 & \\
SI & 0.416 & 0.519 & 0.357 & 0.443 & 0.325 & 0.540 & 0.378 & 0.413 & 0.850 \\
\hline Notes: The diagonal elements (bold) represent the square root of AVE & \\
Source: Author estimations & \multicolumn{10}{c}{ A }
\end{tabular}

The heterotrait-monotrait ratio of correlations (HTMT) result is displayed in table 5 which satisfy the criteria given by (Henseler, Ringle, \& Sarstedt, 2015) thus, none of the variables have values higher than 0.85 (Raza, Qazi, \& Umer, 2016).

Table 5

Heterotrait-Monotrait Ratio (HTMT) Results

\begin{tabular}{|c|c|c|c|c|c|c|c|c|c|}
\hline & $\mathrm{AT}$ & CA & EE & FC & HSE & I & ISE & PE & SI \\
\hline \multicolumn{10}{|l|}{$\mathrm{AT}$} \\
\hline CA & 0.462 & & & & & & & & \\
\hline $\mathrm{EE}$ & 0.342 & 0.360 & & & & & & & \\
\hline $\mathrm{FC}$ & 0.448 & 0.607 & 0.245 & & & & & & \\
\hline HSE & 0.494 & 0.466 & 0.348 & 0.413 & & & & & \\
\hline I & 0.547 & 0.600 & 0.319 & 0.562 & 0.442 & & & & \\
\hline ISE & 0.486 & 0.377 & 0.248 & 0.501 & 0.470 & 0.559 & & & \\
\hline $\mathrm{PE}$ & 0.395 & 0.601 & 0.280 & 0.445 & 0.235 & 0.363 & 0.294 & & \\
\hline SI & 0.451 & 0.609 & 0.386 & 0.507 & 0.367 & 0.568 & 0.407 & 0.483 & \\
\hline
\end{tabular}

Thus, the above results showed the satisfactory results related to the individual item reliability, convergent validity, and discriminant validity so the structural model is assessed.

\section{Structural Model}

The structural model is evaluated by determining the explanatory strength of any model and by inspecting the hypothesis of the research. The explanation strength of the model is evaluated by looking at the value of $\mathrm{R} 2$. In this study, the value of $\mathrm{R} 2$ is 0.502 . This showed that all the independent variables can predict around $50.2 \%$ of the dependent variable i.e., intention. After that, the path analysis was done. Each path displayed a hypothesis. The hypotheses are assessed on the basis of size, sign, and coefficient value. The higher the coefficient value the stronger the association between the dependent and the independent variable. The hypotheses were set to be supported at the significance level of 0.1 . As seen from table 6 in total there were 8 hypotheses and out of 8,5 hypotheses were accepted. The path linking attitude to intention is found significant and 
positive. The path linking computer anxiety and intention is also found significant and negative. The path linking effort expectancy and intention is found positive but insignificant. The path linking facilitating condition and intention is also found significant and positive. The path linking Human-assisted self-efficacy and intention is found positive but insignificant. The path linking individual assisted self-efficacy and intention is found significant and positive. The path linking performance expectancy and intention is found positive but insignificant. The path linking social influence to intention is found significant and positive.

Table 6

Path Analysis

\begin{tabular}{|c|c|c|c|c|}
\hline & & & Coefficients & P-Values \\
\hline AT & $\rightarrow$ & I & 0.149 & 0.031 \\
\hline CA & $\rightarrow$ & I & -0.217 & 0.003 \\
\hline $\mathbf{E E}$ & $\rightarrow$ & I & 0.021 & 0.748 \\
\hline FC & $\rightarrow$ & $\mathbf{I}$ & 0.126 & 0.078 \\
\hline HSE & $\rightarrow$ & I & 0.045 & 0.613 \\
\hline ISE & $\rightarrow$ & I & 0.238 & 0.000 \\
\hline PE & $\rightarrow$ & I & 0.014 & 0.916 \\
\hline SI & $\rightarrow$ & I & 0.192 & 0.001 \\
\hline \multicolumn{3}{|c|}{ R-Square } & \multicolumn{2}{|c|}{0.502} \\
\hline
\end{tabular}

\section{Conclusion and Discussion}

The results showed that the factors that are, social influence, facilitating conditions, individual self-efficacy and the attitude has a significant positive effect on the intention to use technology, whereas, the variable computer anxiety has a significant negative effect and the variables performance expectancy, effort expectancy and human assisted self-efficacy have an insignificant effect on the intention to use technology. The results of social influence, facilitating conditions, individual self-efficacy and attitude were supported by the studies of (Venkatesh et al., 2012; Raman \& Don, 2013; Teo et al., 2008; Teo, 2009; Looney, Valacich, \& Akbulut, 2004; Farahat, 2012) respectively. Further, the result of the variable computer anxiety was support with the study of Raaij \& Schepers (2008). The results of performance, effort expectancy in this study are also supported by the studies of (Attuquayefio \& Addo, 2014; Afshan \& Sharif, 2016; Joo, Joung, Shin, Lim, \& Choi, 2014) respectively. While, the result of human assisted self-efficacy was inconsistent with the studies of (K. Chen, Chen, \& Yen, 2011; Thatcher, Gundlach, McKnight, \& Srite, 2007).

The significant positive effect of social influence, facilitating conditions, individual self-efficacy and the attitude on the dependent variable explains the driving forces of a teacher's intention to use technology. It shows that society, assistance from surrounding, own attitude and an individual's self-reliance and self-image motivates an individual for the intended use of technology. The higher will be the effect of these factors, the more are the chances that an individual will be inclined towards the use of technology. Among these positive factors, the individual self-efficacy is the factor that has the highest significant effect on the intention to use technology as the results indicate the highest coefficient.

The study identified the computer anxiety as the only factor that has a negative impact on the intention to use technology; this implies that more the anxiety the less will be the intention. The results also support that the expectation of an individual to improve his performance and effort reduction through usage of technology has an immaterial effect on the intention to use technology. 


\section{Recommendations and policy implications}

Since, the technology is advancing at a fast pace, it is important for the key stakeholders and management to understand the factors that create hurdles or influence the technology acceptance. The results highlight the important matters that should be considered by the higher education institutes in order to improve the technology usage of higher education teachers. Considering the effects of social influence on increasing intentions to use technology in the study, the higher management of the institutes should provide a culture that encourages the overall acceptance of technology. The top-down approach for the introduction and acceptance of technology will not only benefit the overall organization, but will construct an environment of social acceptance of technology throughout the university. The recent trends of technology and social media in the society; nowadays, are also working to the benefit of higher management of the institutes which may be synergized to enhance the usage of technology. From the implementers' perspective, the developers of the technology should shape a positive perception about their technology as this also increase its adoption rate.

The facilitating conditions also play an important role in building intentions towards the technology usage, the higher management should ensure setting-up of IT Help desk in their institution which should provide technical support for the technologies used and adopted by the university. More focus should be given towards on agreeing service level agreements between user departments and technical departments providing support for the technology. The feedback mechanism should also be established which will assist the IT staff to direct their efforts on solving the teachers' problems effectively. Also, the reliable network access and related guidance will improve the teacher's attitude to using the technology.

To improve the individual self-efficacy of the teachers, the universities may also form work groups who will be involved in User Acceptance Testing (UAT) phase of implementation and will also perform their duties as mentors during the training session for other users. Additionally, management should ensure that extensive training is provided to the teachers for the use of technology because it will help them to gain in-depth knowledge, feel confident and comfortable in using it and will also reduce their anxiety.

\section{Limitations and future research of the study}

The limitation of the study includes that the study is restricted to the business universities of Karachi only. The study covers the higher education teachers' perspective so the result cannot be generalized to the teachers of schools and colleges. Moreover, it focuses the teachers' perspective only and ignores the student's viewpoint.

To take this study further and reap the benefits of this study, similar studies may also be conducted like increasing the population, including all business universities pan Pakistan, at school and college level teachers, by gauging student's perspective towards the technology usage. Also, more variables like actual usage and others may also be added to future studies to understand the impact of other factors collectively and individually.

\section{Contribution of the study}

This study contributes to the literature on technology usage among higher education teachers; the UTAUT model has been used in developed economies and in different industries whereas this study identifies the factors that affect the use of technology in the education sector. Therefore, this research contributes to the existing body of knowledge by providing substantial knowledge on technology use by higher education teachers. 


\section{References}

Abbasi, M. S., Tarhini, A., Elyas, T., \& Shah, F. (2015). Impact of individualism and collectivism over the individual's technology acceptance behaviour: A multi-group analysis between Pakistan and Turkey. Journal of Enterprise Information Management, 28(6), 747-768.

Afshan, S., \& Sharif, A. (2016). Acceptance of mobile banking framework in Pakistan. Telematics and Informatics, 33(2), 370-387.

Ajzen, I. (1991). The theory of planned behavior. Organizational Behavior and Human Decision Processes, 50(2), 179-211.

Alenezi, A. R., Karim, A. M. A., \& Veloo, A. (2010). An empirical investigation into the role of enjoyment, computer anxiety, computer self-efficacy and internet experience in influencing the students' intention to use e-learning: A case study from Saudi Arabian governmental universities. The Turkish Online Journal of Educational Technology, 9(4), 22-34.

Ali, M., \& Raza, S. A. (2015). Service quality perception and customer satisfaction in islamic banks of Pakistan: the modified servqual model. Total Quality Management 8 Business Excellence, 1- 19. doi: 10.1080/14783363.2015.1100517

Anderson, J. C., \& Gerbing, D. W. (1988). Structural equation modeling in practice: A review and recommended two-step approach. Psychological Bulletin, 103(3), 411-421.

Arif, I., Aslam, W., \& Ali, M. (2016). Students' dependence on smartphones and its effect on purchasing behavior. South Asian Journal of Global Business Research, 5(2), 285-302.

Aslam, H. D. (2011). Analyzing professional development practices for teachers in public universities of Pakistan. Mediterranean Journal of Social Sciences, 2(4), 97-106.

Atkinson, M., \& Kydd, C. (1997). Individual characteristics associated with World Wide Web use: an empirical study of playfulness and motivation. ACM SIGMIS Database, 28(2), 53-62.

Attuquayefio, S. N., \& Addo, H. (2014). Using the UTAUT model to analyze students' ICT adoption. International Journal of Education and Development using Information and Communication Technology, 10(3), 75-84.

Baleghi-Zadeh, S., Ayub, A. F. M., Mahmud, R., \& Daud, S. M. (2014). Behaviour intention to use the learning management: integrating technology acceptance model with task-technology fit. Middle-East Journal of Scientific Research, 19(1), 76-84.

Bandura, A. (1986). Social foundations of thought and action: A social cognitive theory. PrenticeHall, Inc, USA.

Chau, P. Y. (2001). Influence of computer attitude and self-efficacy on IT usage behavior. Journal of Organizational and End User Computing, 13(1), 26-37.

Chen, H.-R., \& Tseng, H.-F. (2012). Factors that influence acceptance of web-based e-learning systems for the in-service education of junior high school teachers in Taiwan. Evaluation and Program Planning, 35(3), 398-406.

Chen, K., Chen, J. V., \& Yen, D. C. (2011). Dimensions of self-efficacy in the study of smart phone acceptance. Computer Standards \& Interfaces, 33(4), 422-431.

Chen, S.-C., Liu, S.-C., Li, S.-H., \& Yen, D. C. (2013). Understanding the mediating effects of relationship quality on technology acceptance: an empirical study of e-appointment system. Journal of Medical Systems, 37(6), 1-13.

Chin, W. W. (1998). The partial least squares approach to structural equation modeling. Modern Methods for Business Research, 295(2), 295-336.

Churchill Jr, G. A. (1979). A paradigm for developing better measures of marketing constructs. Journal of Marketing Research, 16(1), 64-73.

Compeau, D., Higgins, C. A., \& Huff, S. (1999). Social cognitive theory and individual reactions to computing technology: A longitudinal study. MIS Quarterly, 23(2), 145-158.

Compeau, D. R., \& Higgins, C. A. (1995). Application of social cognitive theory to training for computer skills. Information Systems Research, 6(2), 118-143. 
Cviko, A., McKenney, S., \& Voogt, J. (2012). Teachers enacting a technology-rich curriculum for emergent literacy. Educational Technology Research and Development, 60(1), 31-54.

Davis, F. D., Bagozzi, R. P., \& Warshaw, P. R. (1989). User acceptance of computer technology: a comparison of two theoretical models. Management Science, 35(8), 982-1003.

Dillon, A. (2001). User Acceptance of Infomration Technology. Encyclopedia of Human Factors and Ergonomics. Taylor and Francis, London.

Falk, R. F., \& Miller, N. B. (1992). A primer for soft modeling. University of Akron Press, USA.

Farahat, T. (2012). Applying the technology acceptance model to online learning in the Egyptian universities. Procedia-Social and Behavioral Sciences, 64 (1), 95-104.

Fornell, C., \& Bookstein, F. L. (1982). Two structural equation models: LISREL and PLS applied to consumer exit-voice theory. Journal of Marketing Research, 19(4), 440-452.

Fornell, C., \& Larcker, D. F. (1981). Evaluating structural equation models with unobservable variables and measurement error. Journal of Marketing Research, 18(1), 39-50.

Hadjipavli, E. (2011). An examination of cypriot teachers' concerns regarding the adoption of a learning management system in secondary education. North Central University, USA.

Hair, J. F., Ringle, C. M., \& Sarstedt, M. (2011). PLS-SEM: Indeed a silver bullet. Journal of Marketing Theory and Practice, 19(2), 139-152.

Hasan, B., \& Ahmed, M. U. (2012). A path analysis of the impact of application-specific perceptions of computer self-efficacy and anxiety on technology acceptance. End-User Computing, Development, and Software Engineering: New Challenges, 354-367. doi: 10.4018/ 978-1-4666-0140-6

He, J., \& Freeman, L. A. (2010). Understanding the formation of general computer self-efficacy. Communications of the Association for Information Systems, 26(1), 12-19.

Henry, J. W., \& Stone, R. W. (1994). A structural equation model of end-user satisfaction with a computer-based medical information system. Information Resources Management Journal, $7(3), 21-33$.

Henseler, J., Ringle, C. M., \& Sarstedt, M. (2015). A new criterion for assessing discriminant validity in variance-based structural equation modeling. Journal of the Academy of Marketing Science, 43(1), 115-135.

Hu, P. J., Chau, P. Y., Sheng, O. R. L., \& Tam, K. Y. (1999). Examining the technology acceptance model using physician acceptance of telemedicine technology. Journal of Management Information Systems, 16(2), 91-112.

Hulland, J., \& of Business, R. I. S. (1999). Use of partial least squares (PLS) in strategic management research: A review of four recent studies. Strategic Management Journal, 20(2), 195-204.

Igbaria, M., \& Iivari, J. (1995). The effects of self-efficacy on computer usage. Omega, 23(6), $587-605$.

Imtiaz, M. A., \& Maarop, N. (2014). A Review of Technology Acceptance Studies in the Field of Education. Jurnal Teknologi, 69(2). doi: 10.11113/jt.v69.3101

John, S. P. (2013). Influence of Computer Self-Efficacy On Information Technology Adoption. International Journal of Information Technology, 19(1), 1-13.

Joo, Y. J., Joung, S., Shin, E. K., Lim, E., \& Choi, M. (2014). Factors influencing actual use of mobile learning connected with e-learning. International Journal of Computer Science $\&$ Information Technology, 6(6), 169-176.

Kim, J. H., Jung, S. Y., \& Lee, W. G. (2008). Design of contents for ICT literacy in-service training of teachers in Korea. Computers $\&$ Education, 51(4), 1683-1706.

Kline, R. B. (2005). Principles and practice of Structural Equation Modeling. Guilford Press, New York. 
Lohmöller, J.-B. (1989). Latent variables three-mode path (LVP3) analysis. Springer Nature, United Kingdom.

Looney, C. A., Valacich, J. S., \& Akbulut, A. Y. (2004). Online investment self-efficacy: Development and initial test of an instrument to assess perceived online investing abilities. Institute of Electrical and Electronics Engineers, New Jersey.

Ma, W. W.-k., Andersson, R., \& Streith, K.-O. (2005). Examining user acceptance of computer technology: An empirical study of student teachers. Journal of Computer Assisted Learning, 21(6), 387-395.

Mueller, J., Wood, E., Willoughby, T., Ross, C., \& Specht, J. (2008). Identifying discriminating variables between teachers who fully integrate computers and teachers with limited integration. Computers \& Education, 51(4), 1523-1537.

Munro, R. (2012). A case study of school-based training systems in New Zealand secondary schools. Informa Limited, UK.

Ngai, E. W., Poon, J., \& Chan, Y. (2007). Empirical examination of the adoption of WebCT using TAM. Computers \& Education, 48(2), 250-267.

Nunally, J. (1967). Psychometric Theory. McGraw Hill, New York.

Raman, A., \& Don, Y. (2013). Preservice teachers' acceptance of learning management software: An Application of the UTAUT2 Model. International Education Studies, 6(7), 157-169.

Raza, S. A., \& Hanif, N. (2013). Factors affecting internet banking adoption among internal and external customers: a case of Pakistan. International Journal of Electronic Finance, 7(1), $82-96$.

Raza, S. A., Qazi, W., \& Umer, A. (2016). Facebook is a source of social capital building among university students evidence from a developing country. Journal of Educational Computing Research. doi: 10.1177/0735633116667357

Ringle, C. M., Wende, S., \& Becker, J.-M. (2015). SmartPLS 3. Revista Brasileira de Marketing, $13(2), 56-73$.

Stantchev, V., Colomo-Palacios, R., Soto-Acosta, P., \& Misra, S. (2014). Learning management systems and cloud file hosting services: A study on students' acceptance. Computers in Human Behavior, 31(1), 612-619.

Sundaravej, T. (2010). Empirical validation of unified theory of acceptance and use of technology model. Journal of Global Information Technology Management, 13(1), 5-27.

Tabachnick, B. G., \& Fidell, L. S. (2001). Principal components and factor analysis. Using Multivariate Statistics, 4 (1), 582-633.

Teo, T. (2009). Modelling technology acceptance in education: A study of pre-service teachers. Computers $\&$ Education, 52(2), 302-312.

Teo, T., Lee, C. B., \& Chai, C. S. (2008). Understanding pre-service teachers' computer attitudes: applying and extending the technology acceptance model. Journal of Computer Assisted Learning, 24(2), 128-143.

Teo, T., \& Milutinovic, V. (2015). Modelling the intention to use technology for teaching mathematics among pre-service teachers in Serbia. Australasian Journal of Educational Technology, $31(4), 363-380$.

Teo, T., \& Noyes, J. (2011). An assessment of the influence of perceived enjoyment and attitude on the intention to use technology among pre-service teachers: A structural equation modeling approach. Computers \& Education, 57(2), 1645-1653.

Teo, T., \& Zhou, M. (2014). Explaining the intention to use technology among university students: a structural equation modeling approach. Journal of Computing in Higher Education, 26(2), 124-142.

Thatcher, J. B., Gundlach, M. J., McKnight, D. H., \& Srite, M. (2007). Individual and humanassisted computer self efficacy: An empirical examination. IEEE Transactions on Engineering 
Management, 55(4), 628-644.

Thomas, T. D., Singh, L., \& Gaffar, K. (2013). The utility of the UTAUT model in explaining mobile learning adoption in higher education in Guyana. International Journal of Education and Development using Information and Communication Technology, 9(3), 71-84.

Venkatesh, V., Morris, M. G., Davis, G. B., \& Davis, F. D. (2003). User acceptance of information technology: Toward a unified view. MIS Quarterly, 27(3), 425-478.

Venkatesh, V., Thong, J. Y., \& Xu, X. (2012). Consumer acceptance and use of information technology: extending the unified theory of acceptance and use of technology. MIS Quarterly, 36(1), 157-178.

Williams, M. R., Warner, W. J., Flowers, J. L., \& Croom, D. B. (2014). Teaching with Technology: North Carolina Agriculture Teachers' Knowledge Acquisition, Attitudes, and Identified Barriers. Journal of Agricultural Education, 55(5), 1-15.

Wong, K.-T., Goh, P. S. C., \& Rahmat, M. K. (2013). Understanding Student Teachers' Behavioural Intention to Use Technology: Technology Acceptance Model (TAM) Validation and Testing. International Journal of Instruction, 6(1), 89-104.

Wong, K.-T., Teo, T., \& Russo, S. (2013). Interactive whiteboard acceptance: Applicability of the UTAUT model to student teachers. The Asia-Pacific Education Researcher, 22(1), 1-10.

Wood, E., Mueller, J., Willoughby, T., Specht, J., \& Deyoung, T. (2005). Teachers' perceptions: Barriers and supports to using technology in the classroom. Education, Communication 8 Information, 5(2), 183-206. 